\title{
High speed marine bacteria use sodium-ion and proton driven motors
}

\author{
James G. Mitchell*, Gregory M. Barbara
}

School of Biological Sciences, Flinders University of South Australia, GPO Box 2100, Adelaide, South Australia 5001, Australia

\begin{abstract}
The ocean's strong ionic environment may be important for motility in marine bacteria. This is because flagellar motors are powered by dissipation of ion gradients across their cell membranes. We tested how much the 2 known motor systems contributed to the high speed motility $\left(>100 \mu \mathrm{m} \mathrm{s}^{-1}\right)$ found in marine bacterial communities and isolates. Monensin, carbonylcyanide-mchlorophenylhydrozone (CCCP) and amiloride were used on Escherichia coli, Shewanella putrefaciens, Alteromonas haloplanktis, a marine isolate (BBAT1) and marine bacterial communities to uncouple sodium-ion and proton gradients from motility. E. coli motility was stopped by $10 \mu \mathrm{M}$ CCCP. Use of any of the 3 uncouplers alone slowed, but did not stop. S. putrefaciens, A. haloplanktis and a community of marine bacteria. A combination of $20 \mu \mathrm{M} \mathrm{CCCP}$ and $20 \mu \mathrm{M}$ monensin stopped S. putrefaciens and $A$. haloplanktis. The same concentration combination reduced marine community speeds by half, but stopped few cells. Above uncoupler concentrations of $30 \mu \mathrm{M}$ speed remained unchanged at about $20 \mu \mathrm{m} \mathrm{s}^{-1}$ for marine bacterial communities. Sodium-ion motors were responsible for about $60 \%$ of marine bacterial speed. From the results it was concluded that most high speed marine bacterial community members used sodium and proton motors simultaneously.
\end{abstract}

KEY WORDS: Marine bacterial motors · Motility · Proton - Sodium-ion · Uncouplers

\section{INTRODUCTION}

Chemotaxis is found in many microbial assemblages and is generally acknowledged as an important means by which bacteria encounter nutrient patches (Blackburn et al. 1998). The ocean is increasingly seen as an environment of many small nutrient patches embedded in a dynamic, organic polymer matrix (Azam et al. 1994, Azam 1998). Modelling predicts that chemotactic capability of bacteria in the ocean can increase their growth rate by $50 \%$ (Blackburn et al. 1997), and experimental work suggests that at least $85 \%$ of water column marine bacteria are capable of motility (Mitchell et al. 1995a). Their movement pattern is modified from the standard 'run and tumble' strategy used by enteric bacteria such as Escherichia coli (Berg \& Brown 1972) and soil bacteria such as Rhizobium meleloti (Götz et al. 1982). Modifications include reversals rather than tumbles and speeds in excess of $200 \mu \mathrm{m} \mathrm{s}^{-1}$, up to 10 times faster than E. coli (Mitchell et al. 1995a). The mecha-

\footnotetext{
•E-mail: jim.mitchell@flinders.edu.au
}

nism of the reversals arises from polar grouping of flagella on the bacterial surface. In contrast, the mechanism and significance of high speed in marine bacteria are more complicated. Due to shear and their small size, speeds of the order of $100 \mu \mathrm{m} \mathrm{s}^{-1}$ are required for successful chemotaxis by marine bacteria (Mitchell 1991, Bowen et al. 1993). Since the power requirement increases as the square of the speed, the energetic cost is high in an environment where nutrient availability is low or intermittent (Morita 1988, Azam 1998). While high speed and cost may be necessary to remain near small nutrient sources in a turbulent ocean, the mechanism is little studied. To better understand the mechanism underlying high speed and chemotaxis in marine communities, this research focused on the motor types that drive marine bacterial flagella.

Flagellate bacteria swim by rotating helical flagella, each driven by a rotary molecular motor embedded in the cytoplasmic membrane and cell wall (Macnab 1987). The motors are powered by an electrochemical gradient of either protons or sodium ions. Motile bacteria can possess either or both motor types. Escherichia 
coli possess only proton-driven motors, alkalophilic Bacillus species use only sodium motors, while the marine species Vibrio alginolyticus, uses proton and sodium-ion driven motors (Macnab 1987, Imae \& Atsumi 1989, Atsumi et al. 1996). The difference in the motors extends beyond the ions that power them. $E$. coli and other proton-driven bacteria have motors that rotate at a few hundred revolutions per second (rps) (Lowe et al. 1987, Berry et al. 1995), whereas the sodium-ion motors of $V$. alginolyticus rotate between 1000 and 1700 rps, with accompanying speeds of up to $150 \mu \mathrm{m} \mathrm{s}^{-1}$ (Magariyama et al. 1994). The dual motor system is believed to reflect distinct physical environments in which different bacteria live, where proton motors are used in high viscosity environments (ca $10 \mathrm{cP}$ ), while sodium-ion motors are used in low viscosity environments (ca $1 \mathrm{cP}$ ) (Atsumi et al. 1996).

The manner and extent to which double motors are used in the marine microbial community has not been evaluated. Similarly, it is unknown what fraction of the total speed for a bacterium is driven by sodium-ion motors and whether dual motor systems occur beyond the genus Vibrio. It is possible that a large fractional speed contribution by a sodium ion dependent motor could limit high bacterial speeds to the marine, or other high salt, environments. The objectives of the present research were to investigate the fractional speed contribution made by proton and sodium-ion motors in marine bacteria. To achieve this objective, and get the most realistic result possible, samples of natural communities were included in this study. To build a foundation for future experimental research, the same experiments were carried out on recent, but stable, isolates.

\section{MATERIALS AND METHODS}

Sampling and isolation. Samples were collected from the water column, approximately $50 \mathrm{~m}$ from shore, at Brighton Beach, South Australia, and kept in $500 \mathrm{ml}$, sterile, glass bottles at 21 to $23^{\circ} \mathrm{C}$ for $24 \mathrm{~h}$. This isolated bacteria from nutrient sources, such as particles resuspended from the benthos, and was done to increase the fraction of motile cells (Mitchell et al. 1995a). To increase cell number and stimulate motility, $10 \%$ tryptic soy broth (TSB) in sterile seawater was added to produce a final concentration of $0.1 \%$ TSB. Strains of Shewanella putrefaciens, Alteromonas haloplanktis and an unidentified isolate, BBAT1, all from Brighton Beach (Mitchell et al. 1995a,b, 1996), as well as Escherichia coli ATCC 29922 were used for comparison with the enriched seawater community. E. coli was grown in $0.1 \%$ TSB broth cultures overnight while the marine isolates were grown in $0.1 \%$ TSB, autoclaved, filter sterilised seawater from Brighton Beach. The pHs for $E$. coli, the isolates and the bacterial community were 7.4 (unadjusted), 8.2 and 8.3 (adjusted with $1 \mathrm{M}$ $\mathrm{NaOH}$ ), respectively. To assess the influence of $\mathrm{NaCl}$ on isolate speeds, A. haloplanktis and S. putrefaciens were grown in 1,2, 3 and $4 \%$ artificial seawater. Motility parameters were determined as described below.

Motility measurements and ion uncoupler useage. Cell speed was measured by bright-field microscopy using frame-by-frame analysis of video images (Barbara \& Mitchell 1996). High speed and cluster formation were induced by the introduction of millimetersize air bubbles underneath a coverslip containing bacteria. The percent of motile population or community was measured directly from video images according to Mitchell et al. (1995a).

The addition of ion gradient uncouplers and inhibitors, specifically the sodium-ion uncoupler monensin (10 to $60 \mu \mathrm{M})$ and the protonophore carbonylcyanidem-chiorophenyihydruzone (CCCP, 3 to $30 \mu \mathrm{M}$ ) were used to determine the type of motor being used (Atsumi et al. 1992b). The sodium-ion uncoupler monensin was used in place of the more traditional amiloride for the natural communities and the 2 identified isolates because the former is less toxic to other cell functions and works at a thousandth the concentration of amiloride (Dibrov et al. 1986, Atsumi et al. 1992a). To provide a link and comparison with the amiloride literature, which established sodium-ion uncoupling (Atsumi et al. 1992a), an unidentified isolate, BBAT1, tolerant to amiloride was also included in the experiments.

Alteromonas haloplanktis and Shewanella putrefaciens were either grown in broth as described above with the either $\mathrm{MgCl}_{2}$ or $\mathrm{KCl}$ substituted for $\mathrm{NaCl}$ at concentrations of $3.5 \%$, or grown in standard broth, pelleted at $5000 \times g$ for $5 \mathrm{~min}$ and then resuspended in $\mathrm{MgCl}_{2}$ or $\mathrm{KCl}$. In the latter case, cell speeds were recorded within $10 \mathrm{~min}$ of resuspension.

Transmission electron microscopy. Methods were modified from McCarter et al. (1988). Slot grids coated with $0.5 \%$ butvar were inverted for $5 \mathrm{~min}$ on drops of broth cultures previously fixed with $10 \%$ paraformaldehyde and $12.5 \%$ glutaraldehyde in $0.15 \mathrm{M}$ sodium cacodylate buffer at $\mathrm{pH} 7.4$. Grids were washed 4 times, stained for $5 \mathrm{~s}$ with $0.5 \%$ phosphotungstic acid, dried and examined with a Phillips 100 microscope at $80 \mathrm{kV}$.

\section{RESULTS AND DISCUSSION}

\section{Speed alteration in an enteric standard}

Escherichia coli showed no clustering behavior and moved at speeds ranging from 2 to $40 \mu \mathrm{m} \mathrm{s}^{-1}$ (Fig. 1). 


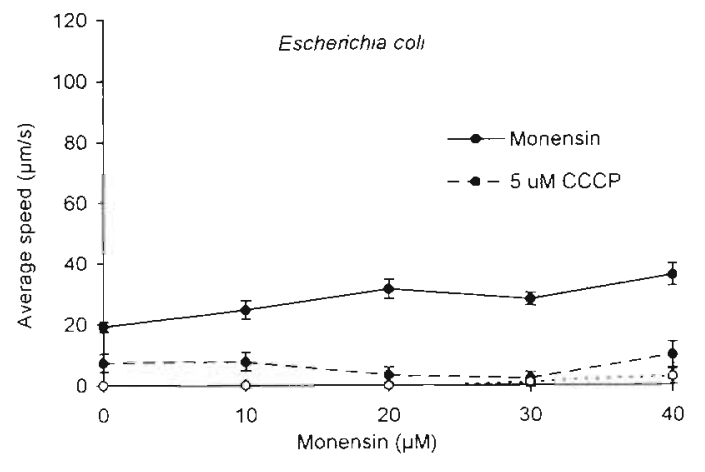

Fig. 1 Speed of Escherichia coli as a function of monensin concentration. Broken lines indicate the presence of both monensin and CCCP. Error bars are $95 \%$ confidence intervals. The resolution of the method is $2 \mu \mathrm{m} \mathrm{s}^{-1}$

The speed of E. coli doubled over a $40 \mu \mathrm{M}$ change in monensin alone to approximately the maximum reported in the literature (Macnab 1987) and was reduced to zero in $10 \mu \mathrm{M} \mathrm{CCCP}$, consistent with its known use of proton-driven motors (Macnab 1987). These results suggest that counter-ion transport from the $3 \mathrm{mM} \mathrm{NaCl}$ in TSB, rather than the ability of the motors to pump out sodium-ions, limited speed. The conflicting action of monensin and CCCP, at approximately equimolar concentrations, caused the decrease in speed (Fig. 1) to be less than when just CCCP was present (Fig. 2).

\section{Speed alteration with CCCP for marine isolates and communities}

The isolates, Shewanella putrefaciens and Alteromonas haloplanktis, formed 50 to $100 \mu \mathrm{m}$ wide clusters around small air bubbles, utilising a run and reverse pattern of movement seen in the bacterial communities of this study and in previous work (Mitchell et al. 1996). Unlike Escherichia coli, both isolates maintained motility at CCCP concentrations above $10 \mu \mathrm{M}$ (Fig. 2). Their sensitivities to CCCP were similar in that both showed small speed increases between 0 and $3 \mu \mathrm{M}$, probably due to increased counter-ion transport of sodium-ions, similar to what was observed with E. coll and monensin (Figs. $2 \& 3$ ). However, above $3 \mu \mathrm{M} \mathrm{CCCP}, S$. putrefaciens maintained or increased speed up to $20 \mu \mathrm{M}$ (Fig. 2), while A. haloplanktis showed an approximately linear decline in speed from $3 \mu \mathrm{M}$, slowing by a factor of 4 across a 5 -fold concentration increase ( 3 to $15 \mu \mathrm{M} \mathrm{CCCP}$, Fig. 3). The results indicate that a proton motor inhibitor was not sufficient to stop $S$. putrefaciens and $A$. haloplanktis, even though it slowed them down. The reason for the broad peak of speed increase in $S$. putrefaciens is unclear, but seems to indicate higher

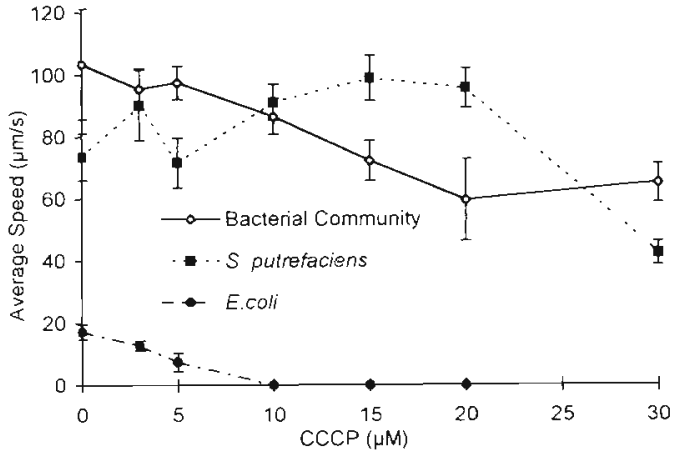

Fig. 2. Influence of CCCP on the speed of Escherichia coli, Shewanella putrefaciens and marine bacterial communities The increasing error bars up to $20 \mu \mathrm{M}$ in the bacterial community are believed to reflect the diversity of response to CCCP in the community. Error bars are $95 \%$ confidence intervals

resistance to $\mathrm{CCCP}$ than $A$. haloplanktis possesses. The single point peak for $S$. putrefaciens at $3 \mu \mathrm{M}$ was significantly different from 0 or $5 \mu \mathrm{M}(\mathrm{p}=0.005$ and $p=0.002$, 2 -tailed $t$-tests assuming unequal variance). The rise from 0 to $3 \mu \mathrm{M}$ may be the result of a counter-ion transport phenomenon, similar to that of Fig. 1. The taxonomic level at which variation in resistance and counterion transport occurred was not ascertained, but recent work (Ziemke et al. 1997) indicates that at least $S$ putrefaciens shows considerable intraspecies genetic variability that precludes attribution of the difference to simple interspecies differences.

Overall, the results of isolates with CCCP indicated that proton driven motors were only partly responsible for their motility. This was further supported by the response of the bacterial community to CCCP. There was no observerd counter-ion speed increase in the bacterial community; rather, CCCP reduced speed by $40 \%$ from approximately 100 to $60 \mu \mathrm{m} \mathrm{s}^{-1}$ between 0 and $20 \mu \mathrm{M}$ (Fig. 2), leveling out thereafter.

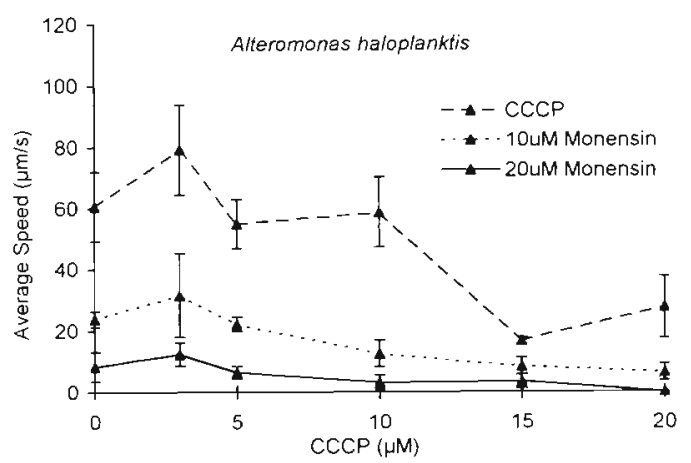

Fig. 3. Response of Alteromonas haloplanktis to CCCP alone and $\mathrm{CCCP}$ amended with 10 or $20 \mu \mathrm{M}$ monensin. Error bars are $95 \%$ confidence intervals. Where error bars are not visible, they are smaller than the symbol 


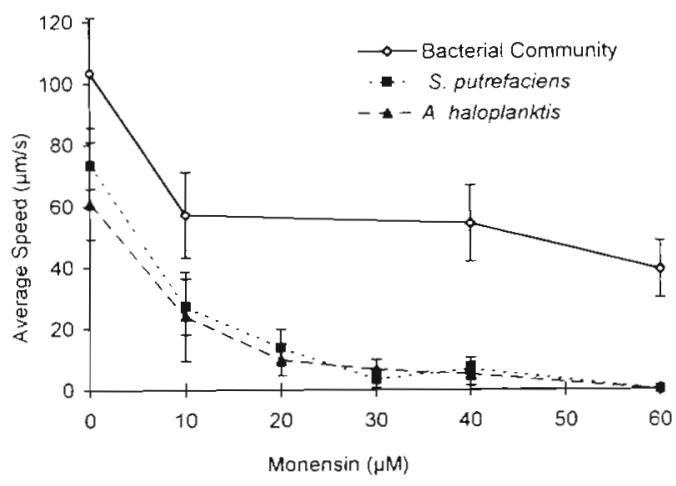

Fig. 4. Influence of monensin on the 2 marine isolates and the bacterial community. The zero micromolar monensin points serve as references for this figure and Fig. 5. Error bars are $95 \%$ confidence intervals

\section{Speed alteration with monensin and amiloride for marine isolates and communities}

The hypothesis that sodium ions were responsible for much of the isolate and community motility was tested and confirmed using monensin and amiloride. For Alteromonas haloplanktis, the presence of 10 and $20 \mu \mathrm{M}$ monensin significantly reduced speed at all CCCP concentrations, compared to CCCP alone (Fig. 3). Monensin alone stopped motility in both isolates at $60 \mu \mathrm{M}$ and reduced speed in the bacterial community by $60 \%$ (Fig. 4). A combination of $20 \mu \mathrm{M} \mathrm{CCCP}$ and $20 \mu \mathrm{M}$ monensin stopped both isolates and reduced the bacterial community speed by $65 \%$ (Fig. 5). Similarly, the BBAT1 isolate in $2.5 \mathrm{mM}$ amiloride showed a speed reduction of approximately $65 \%$ (data not plotted, treatment speed/initial speed = $\left(28 \mu \mathrm{m} \mathrm{s}^{-1}\right) /\left(81 \mu \mathrm{m} \mathrm{s}^{-1}\right), 95 \%$ confidence intervals for both values $\left.=9 \mu \mathrm{m} \mathrm{s}^{-1}\right)$.

\section{Influence of speed alteration on motile fraction}

The results presented here indicate that sodium-ion motors are responsible for at least $60 \%$ of marine bacterial speed in 1 species of Shewanella, 1 species of Alteromonas, and an unidentified isolate. The speed reduction caused by the uncouplers was probably achieved through both direct effects, on the motors, and indirect effects, by acting as a metabolic poison. Vibrio alginolyticus, for example, grew at $\mathrm{pH} 7$, but failed to grow at $\mathrm{pH} 8.5$ when amiloride was present (Atsumi et al. 1992a). From this work it appears that the balance between poisoning and specific motor inhibition is species and condition dependent. Ultimately, completely separating the 2 effects is probably impossible since a transmembrane ion gradient powers cell metabolism and 1 of the 2 motor types. The results, then, first show a species' reliance on sodium ion gradients versus proton gradients. To go beyond this, and gain at least a qualitative understanding of the balance between general poisoning and specific motor inhibition, speed against motile fraction was plotted (Fig. 6). The reasoning is that if a compound tends towards being a motor-specific inhibitor, the mean population speed will be reduced while the motile population fraction remains constant and if a compound tends towards being a general poison the fraction of motile cells in the population will be reduced as cells are killed. Visually comparing the slopes of Fig. 6a (CCCP) with those of Fig. 6b (monensin and amiloride), shows that the former appears as a specific inhibitor and the sodium-ion uncouplers appear more poisonous. This is not conclusive and may be further support that these marine bacteria are just more dependent on sodiumion gradients than proton gradients. This may also explain why there was no difference in the slope of amiloride and monensin additions for the bacterial communities in Fig. 6b. The increase in motile fraction of Escherichia coli cells was likely an artefact of counter-ion transport.

\section{Accounting for the maintenance of speed in the presence of uncouplers}

Despite the speed reductions, marine bacterial communities maintained speeds of at least $30 \mu \mathrm{m} \mathrm{s}^{-1}$ at uncoupler concentrations that rendered the isolates immotile (Figs. $4 \& 5$ ). The maintenance of speed in the presence of uncouplers could have been caused by a low uncoupler molecule to cell ratio or by resistance to the uncouplers (Krulwich et al. 1990). An uncoupler to cell ratio was calculated by counting the number of cells per unit volume, averaging across the

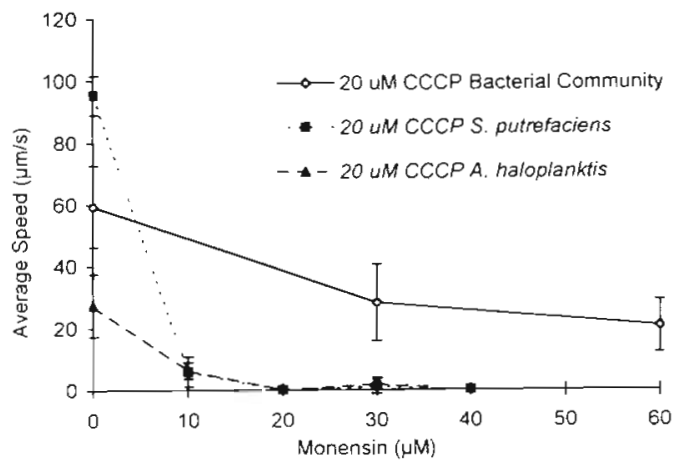

Fig. 5. Combined influence of monensin and CCCP on the speed of the isolates and bacterial community. The zero micromolar monensin points contained $20 \mu \mathrm{M} \mathrm{CC.CP}$ and as such bacterial community speeds were similar to the $20 \mu \mathrm{M}$ CCCP speeds, but lower than in Fig. 4, where only monensin was used. Error bars are $95 \%$ confidence intervals 

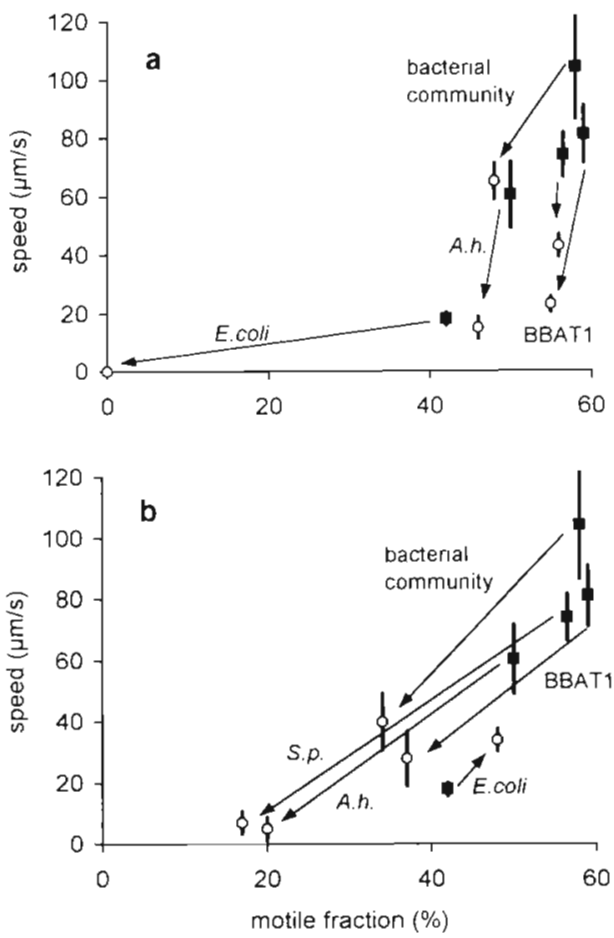

Fig. 6. Changes in mean population or community speed as a function of motile fraction. The arrows are intended to show shifts in behaviour. The interdependence of speed and motile fraction force low and zero values on either axis to the origin Arrows indicate how both parameters changed after the addition of (a) CCCP or (b) Monensin. The response of bacterial communities to amiloride was statistically indistinguishable from the response to monensin and is not shown here for the sake of clarity. BBAT1 was tested with amiloride here for comparison with the bacterial community. Abbreviations are: S.p. Shewanella putrefaciens; A.h., Alteromonas haloplanktis; and BBAT1, an amiloride tolerant isolate. The S.p. label was left off of the small downward arrow in (a) for clarity. Error bars are $95 \%$ confidence intervals. The $x$-axis $95 \%$ confidence intervals for motile fraction were less than $15 \%$ and left off for clarity

coverslip and converting uncoupler concentration to number of molecules. There were between $10^{5}$ and 4 $\times 10^{6}$ uncoupler molecules per cell across all experiments. Even if most of the cell surface receptors were ion pumps, the uncouplers would still be in excess by a factor of 100 to 1000 . From this we conclude that speed maintenance by the marine community took place in the presence of sufficient uncoupler to stop the cells, provided these bacteria are physiologically similar to Escherichia coli, Alteromonas haloplanktis or Shewanella putrefaciens. Resistance to the uncouplers seems the likely explanation for the maintenance of speed. Resistance mechanisms may include inefficient uncoupler uptake due to unusual membrane lipids (Jung et al. 1993), uncoupler binding proteins (Krulwich et al. 1990) or the presence of motors driven by ions other than sodium ions or protons.
Although this latter explanation is unlikely, our data does not permit us to rule it out. Identifying the mechanism of resistance is a worthwhile goal as it is likely to shed light on how marine bacteria achieve comparatively high speeds and more broadly shed light on their physiological linkages with the marine environment.

\section{Influence of $\mathrm{pH}$, salinity and ion substitution on speed}

For our isolates, pH between 7.2 and 9.2 had a pronounced impact on speed and stimulated our original interest in the balance between proton and sodium motors (Dillon 1994). The ocean is well buffered with a pH in suface waters between 8.1 and 8.3 (Millero \& Sohn 1992). As the ultimate goal is to understand the function of marine bacterial communities, $\mathrm{pH}$ in this study was restricted to 8.2 or 8.3 , except for Escherichia coli. Salinity is much more variable than $\mathrm{pH}$ in surface waters and produced ambiguous results in Dillon (1994). Here we present the influence of $\mathrm{NaCl}$ on speed in Fig. 7 for these same isolates. The close correlation between speed and salinity supports the inferences from the uncoupler results that sodium ion motors are important in the motility of marine bacteria. This is further supported by the ion substitution results. The isolates were moderate obligate halophiles, showing no appreciable growth or motility when $\mathrm{MgCl}_{2}$ or $\mathrm{KCl}$ were substituted for $\mathrm{NaCl}$. Resuspended Alteromonas haloplanktis had speed reductions in $\mathrm{MgCl}_{2}$ and $\mathrm{KCl}$ of 70 and $49 \%$ (95\% confidence intervals $=13$ and $17 \%$ ). Resuspended Shewanella putrefaciens had speed reductions in $\mathrm{MgCl}_{2}$ and $\mathrm{KCl}$ of 56 and $38 \%$ (95\% confidence intervals $=12$ and $33 \%$ ).

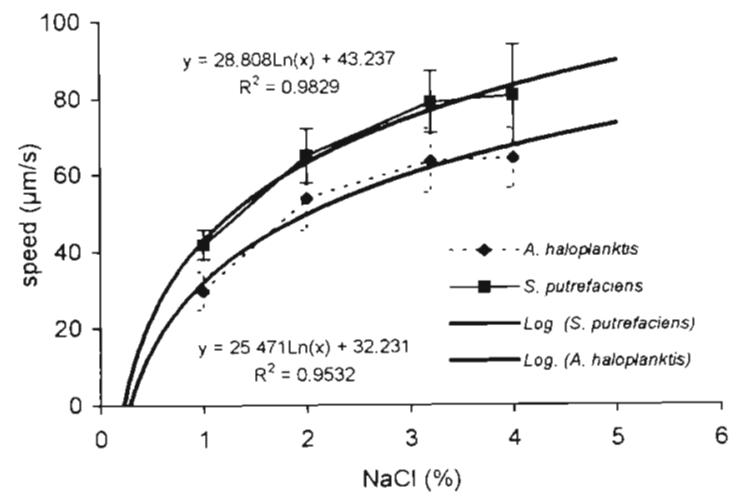

Fig. 7. Influence of sodium chloride concentration on swimming speed for 2 marine bacterial strains. Solid lines are the best fit $\log$ equations (shown with $\mathrm{R}^{2}$ values). Error bars are $95 \%$ confidence intervals. Extrapolations are illustrative of curve shape 


\section{Interpretation}

Sodium-ion motors appear to be an integral part of the high speeds observed in marine bacteria. The hypothesis supported here is that both motor types are used simultaneously. This requires, at least, that cells possess multiple flagella in broth culture. Fig. 8 confirms that Alteromonas haloplanktis and Shewanella putrefaciens possess multiple flagella in culture. To date the presence of dual motors has been identified in Vibrio (Magariyama et al. 1995) and here in Shewanella, Alteromonas and an isolate characterised by growth tolerance to amiloride. Furthermore, natural

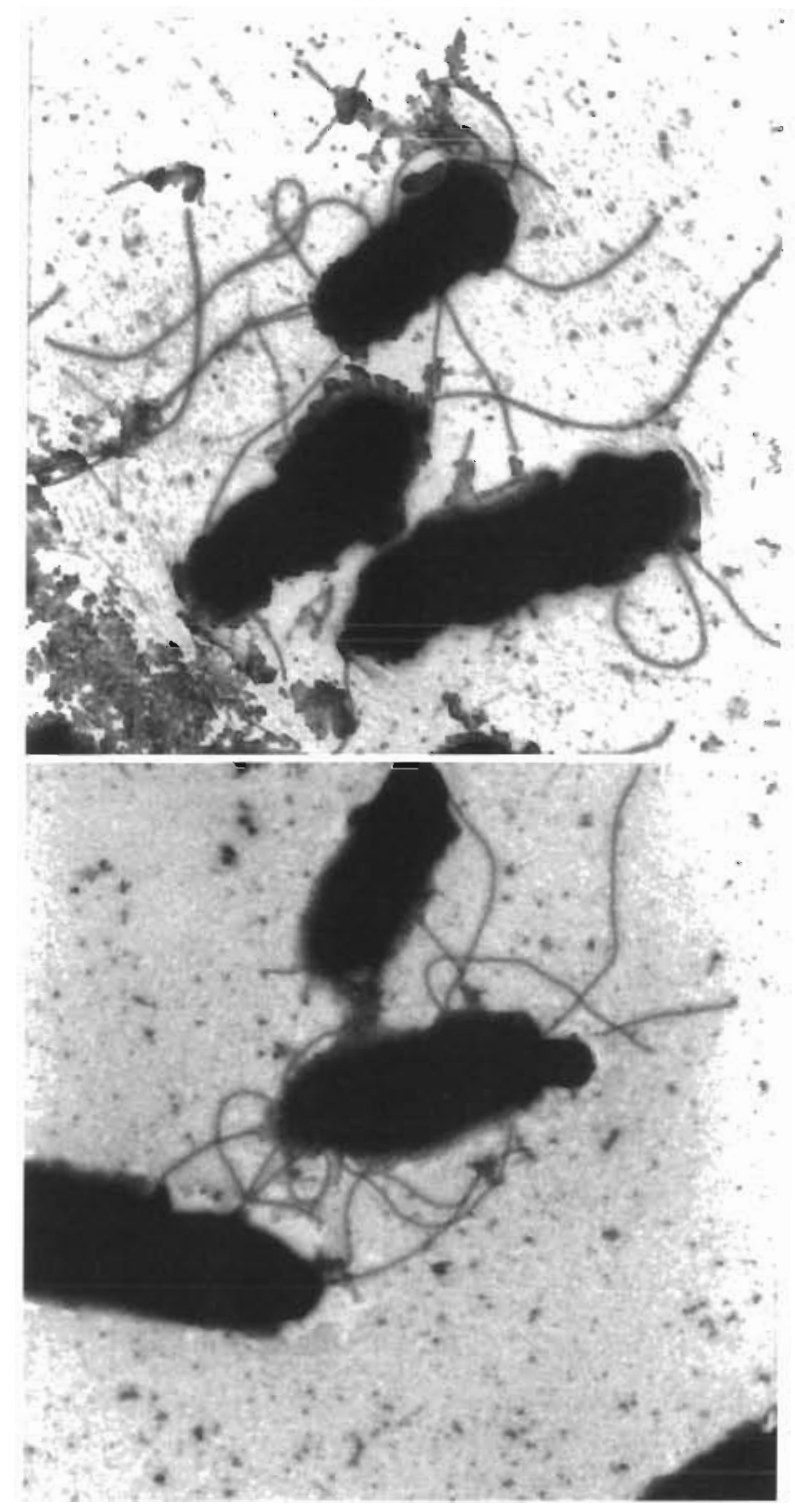

Fig. 8. TEM of (a) Alteromonas haloplanktis and (b) Shewanella putrefaciens showing multiple flagella per cell originating at polar and subpolar positions communities were slowed by high monensin concentrations, but unlike the isolates, showed partial resistance to its ion dissipating effects. The simultaneous use of proton and sodium-ion motors in the low viscosity environment of seawater may be necessary to reach the high speeds useful for positional control near small nutrient patches (Azam et al. 1994, Azam 1998, Blackburn et al. 1998).

Acknowledgements. The authors thank B. Kranz and M. Hale for critically reading the manuscript. L. Pearson provided valuable technical support. The Australian Research Council and the Flinders University of South Australia funded this research

\section{LITERATURE CITED}

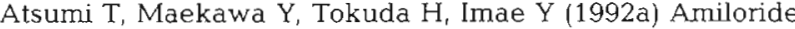
at $\mathrm{pH} 7.0$ inhibits the $\mathrm{Na}^{+}$-driven flagellar motors of Vibrio alginolyticus but allows cells growth. FEBS $314: 114-116$

Atsumi T, McCarter L, Imae Y (1992b) Polar and lateral flagellar motors of marine Vibrio are driven by different ionmotive forces. Nature 355:182-184

Atsumi T, Maekawa Y, Yamada T, Kawagishi I, Imae $Y$ Homma M (1996) Effect of viscosity on swimming by the lateral and polar flagella of Vibrio alginolyticus. J Bacteriol 178:5024-5026

Azam F (1998) Microbial control of oceanic carbon flux: the plot thickens. Science 280:694-696

Azam F, Smith DC, Steward GF, Hagström $\AA$ (1994) Bacteriaorganic matter coupling and its significance for oceanic carbon cycling. Microb Ecol 28:167-179

Barbara GM, Mitchell JG (1996) Formation of 30- to 40micrometer thick laminations by high-speed marine bacteria in microbial mats. Appl Environ Microbiol 62 : 3985-3990

Berg HC, Brown DA (1972) Chemotaxis in Escherichia coli analysed by three-dimensional tracking. Nature 239: 500-504

Berry RM, Turner L, Berg HC (1995) Mechanical limits of bacterial flagellar motors probed by electrorotation. Biophys $\mathrm{J}$ 69:280-286

Blackburn N, Azam F, Hagström \& (1997) Spatially explicit simulations of a microbial food web. Limnol Oceanogr 42 : $613-622$

Blackburn N, Fenchel T, Mitchell J (1998) Microscale nutrient patches in planktonic habitats shown by chemotactic bacteria. Science 282:2254-2256

Bowen JD, Stolzenbach KD, Chisholm SW (1993) Simulating bacterial clustering around phytoplankton cells in a turbulent ocean. Limnol Oceanogr 38:36-51

Dibrov PA, Kostyrko VA, Lazarova RL, Skulanchev VP, Smirnova IA (1986) The sodium cycle I. $\mathrm{Na}^{+}$-dependent motility and modes of membrane energization in the marine alkotolerant Vibrio alginolyticus. Biochem Biophys Acta 850:449-457

Dillon S (1994) Motility and energetics of high speed marine bacterial communities and isolates. Thesis, Flinders University of South Australia

Götz R, Limmer N, Ober K, Schmitt R (1982) Motility and chemotaxis in two strains of Rhizobium with complex flagella. J Gen Microbiol 128:789-798

Imae Y, Atsumi T (1989) $\mathrm{Na}^{+}$-driven bacterial flagellar motors. J Bioener Biomem 21:705-716 
Jung S, Lowe SE, Hollingsworth RI, Zeikus JG (1993) Sarcina ventriculii synthesizes very long chain dicarboxylic acids in response to different forms of environmental stress. J Biol Chem 268:2828-2835

Krulwich TA, Quirk PG, Guffanti AA (1990) Uncoupler-resistant mutants of bacteria. Microbiol Rev 54:52-65

Lowe G. Meister M, Berg HC (1987) Rapid rotation of flagellar bundles in swimming bacteria. Nature 325:637-640

Macnab RM (1987) Motility and chemotaxis. In: Neidhardt FC, Ingraham JL, Low KB, Magasanik B, Schaechter M, Umbarger HE (eds) Escherichia coli and Salmonella typhimurium: cellular and molecular biology, Vol 1. American Society for Microbiology, Washington, DC, p 732-759

Magariyama Y, Sugiyama S, Muramoto K, Maekawa Y, Kawagishi I, Imae Y, Kudo S (1994) Very fast flagellar rotation. Nature 371:752

Magariyama $Y$, Sugiyama S, Muramoto $K$, Maekawa $Y$, Kawagishi I, Imae Y, Kudo S (1995) Simultaneous measurement of bacterial flagellar rotation rate and swimming speed. Biophys J 69:2154-2162

McCarter L, Hilmen M, Silverman M (1988) Flagellar dynamometer controls swarmer cell differentiation of $V$. parahaemolyticus. Cell 54:345-351

Editorial responsibility: Farooq Azam,

La Jolla, California, USA
Millero FJ, Sohn ML (1992) Chemical oceanography. CRC Press, London

Mitchell JG (1991) The influence of cell size on marine bacterial motility and energetics. Microb Ecol 22: $227-238$

Mitchell JG, Pearson L, Bonazinga A, Dillon S, Khouri H, Paxinos $R$ (1995a) Long lag times and high velocities in the motility of natural assemblages of marine bacteria. Appl Environ Microbiol 61:877-882

Mitchell JG, Pearson L, Dillon S, Kantalis K (1995b) Natural assemblages of marine bacteria exhibiting high speed motility and large accelerations. Appl Environ Microbiol 61:4436-4440

Mitchell JG, Pearson L, Dillon S (1996) The behavior of motile marine bacterioplankton communities clustering in narrow bands. Appl Environ Microbiol 62:3716-3721

Morita RY (1988) Bioavailability of energy and its relationship to growth and starvation survival in nature. Can J Microbiol $34: 436-441$

Ziemke F, Brettar I, Höfle MG (1997) Stability and diversity of the genetic structure of a Shewanella putrefaciens population in the water column of the central Baltic. Aquat Microb Ecol 13:63-74

Submitted: July 30, 1998; Accepted: February 5, 1999

Proofs received from author(s): August 3, 1999 